Int. J. Electrochem. Sci., 15 (2020) 1840 - 1852

\title{
Optimization and Application of Potentiometric Stripping Analysis for Determination of Heavy Metals in the samples of Aronia melanocarpa (Michx.) Elliot
}

\author{
Biljana Kaličanin ${ }^{1, *}$, Aleksandra Pavlović ${ }^{2}$, Dragan Velimirovićl, Ivana Arsić ${ }^{1}$, \\ Sofija Đorđevic ${ }^{3}$, Vanja Tadic ${ }^{3}$ \\ ${ }^{1}$ University of Niš, Faculty of Medicine, Department of Pharmacy, 81dr Zoran Đinđić Boulevard, \\ 18000 Niš, Serbia. \\ ${ }^{2}$ University of Niš, Faculty of Sciences and Mathematics, Department of Chemistry, Višegradska 33, \\ 18000 Niš, Serbia. \\ ${ }^{3}$ Institute for Medicinal Plant Research "Dr Josif Pančić", Department for Pharmaceutical Research \\ and Development, Tadeuša Košćuška 1, 11000 Belgrade, Serbia. \\ *E-mail: bkalicanin@yahoo.com
}

doi: $10.20964 / 2020.02 .64$

Received: 11 December 2018 / Accepted: 17 December 2019 / Published: 31 December 2019

\begin{abstract}
Lately, in the group of medicinal herbs, a significant place in the prevention and treatment of certain diseases is taken by Aronia, black chokeberry, Aronia melanocarpa (Michx.) Elliot, Rosaceae. Aronia is a rich source of phenolic substances, mainly flavonoids from the anthocyanin subclass which are responsible for its high antioxidant activity. In addition to the above mentioned compounds, in this plant species heavy metals such as lead and cadmium can be found in the extraction. The aim of this paper was to determine the content of $\mathrm{Zn}, \mathrm{Cd}, \mathrm{Cu}$, and $\mathrm{Pb}$ in samples of fresh Aronia berries, in the juice obtained by cold washing of fresh berries, as well as in the plant material that is left behind after squashing. To determine the content of these metals in these samples, the potentiometric stripping analysis (PSA) with oxygen as an oxidant was used. Zinc and copper biometals were detected in the tested samples of Aronia (berry, juice and the rest of the Aronia berry after squeezing). The content of Zn determined ranged within the limits prescribed for this biometal, while in the tested samples the content of $\mathrm{Cu}$ was higher than those prescribed as recommended daily doses. In the tested Aronia samples, heavy toxic metals, lead and cadmium were also detected. The contents of these metals were low, and significantly below the content that could have harmful and toxic effects on human health. All results were confirmed by parallel ICP-OES comparative analysis. The low values for the average relative deviation $(\delta)$ indicate that there is a good agreement between the results for the content of all detected metals $(\mathrm{Zn}, \mathrm{Cd}, \mathrm{Pb}$ and $\mathrm{Cu}$ ) obtained using the PSA technique with oxygen as an oxidant, and the ICP-OES technique.
\end{abstract}

Keywords: Medicinal plants; Aronia; Heavy metals; PSA; ICP-OES; 


\section{FULL TEXT}

(C) 2020 The Authors. Published by ESG (www.electrochemsci.org). This article is an open access article distributed under the terms and conditions of the Creative Commons Attribution license (http://creativecommons.org/licenses/by/4.0/). 